\title{
INTERRELATING ECOLOGY AND HEALTH: SOME BIO-SOCIAL CONCERNS
}

\author{
Reetinder Kaur \\ Department of Anthropology, Panjab University, Chandigarh, India \\ Email: reetinder1986@gmail.com
}

\begin{abstract}
Ecology and health issues are often characterized by complex interactions between ecosystems and social systems, and demand integration of themes that span the environmental and socioeconomic determinants of health. The present paper emphasizes the health implications of interactions between human groups and their social, physical and biological environments which help in understanding how changes and fluctuations in ecology affects rate and pattern of diseases.
\end{abstract}

Key words: Ecology, ecological anthropology, culture, health and disease.

\section{INTRODUCTION}

The term ecology pertains broadly to the interrelations between organisms and their environments (Hawley 1950). Bates (1953) defined ecology as "the study of entire assemblages of living organisms and their physical milieus, which constitute integrated systems". Ordinarily, ecology is "adaptation to environment". The term adaptation is the process by which the human beings make effective use of productive ends of the energy potential in their habitat. From its early roots in biology, the ecological paradigm has evolved within several disciplines including anthropology, sociology, psychology, economics and public health to provide a general framework for understanding people's transactions with their physical and socio-cultural surroundings.

Health has been defined in a variety of ways; derived from philosophy, from practice and from the experience of ill-health or disability; can be defined in a selective and or universal ways. Selective definitions of health apply only to individuals who exhibit manifestations of ill-health that lead them or their family/care givers to seek health care interventions. These includes those who are not currently exhibiting manifestations of illness or disease processes and those who are exhibiting symptoms of illness and disease processes.

The field of ecology and health examines the direct and interactive effects of conditions in the physical and socio-cultural environment on the physiological, emotional and social well-being of individuals and groups. Ecological analysis provide for the joint influence of biogenetic, psychological, behavioural, socio-cultural and physical environmental factors on human wellbeing than the narrowly-gauged biomedical, 
behavioural and environmental theories. Ecology and health issues are often characterized by complex interactions between ecosystems and social systems, and demand integration of themes that span the environmental and socioeconomic determinants of health.

\section{Ecosystems and health: Landmarks in anthropology}

Ecological anthropology focuses upon the complex relations between people and their environments. Human populations, socially organized and oriented by means of particular cultures, have ongoing contact with and impact upon the land, climate, plant and animal species, and other human beings in their environment and these in turn have reciprocal impacts. Ecological anthropology directs attention to the ways in which a particular population purposely or unintentionally shapes its environment, and the ways in which its relations with the environment shape its culture and its social, economic and political life.

The studies on man-environment relationships in anthropology are two-way: one, studying the effect of environment on man and other, studying the effect of man on environment (Salzman and Attwood 2002). There are several points upon which the ecological anthropologists agree: any particular population is not engaged with the total environment which surrounds it, but rather with certain selected aspects or elements, which may be called its habitat; and the particular place which it occupies may be labelled as niche. Each population has its own orientation or adaptation to a wider environment, institutionalized in the culture of a group, particularly in its technology which includes established knowledge of plants and animals, weather and minerals, as well as tools for extracting food, clothing and shelter.

Some of the early anthropologists like Boas, Malinowski and Radcliffe-Brown examined the relationships within the social and cultural realm with little direct attention to relations with the environment. Notwithstanding Forde's (1934) early contribution and some relevant ethnographic reports, ecological anthropology became fully established in 1960s. In the late 1960s and 1970s, the ecological anthropology was inspired by the concept of cultural ecology (Steward 1968). The 'cultural ecology' is the study of the processes by which a society adapts to its environment. Its principal problem is to determine whether these adaptations initiate internal social transformations of evolutionary change. Like 'biological ecology', which analyses adaptation to the complex interconnections that makes an environment, cultural ecology is a view of 'man in web of life' (Steward 1973).

White (1959) propounded that all cultures consists of three essential components. He referred to these components as the techno-economic, the social, and the ideological. White defined the techno-economic aspect of a culture as the way in which the members of the culture deal with their environment, and it is this aspect which then determines the social and ideological aspects of the culture. In effect, White combined the principles of economic and environmental determinism. He considered the manner in which a culture adapts to its environment as the most significant factor in its development.

The concept of cultural ecology gave way to the concept of political ecology such that ecological and medical anthropologists are now working in urban and industrial settings, where environmental issues and health inequities related to class, race, and place demanded their attention. Medical anthropology studies the human health in variety of environmental and cultural contexts ranging from isolated tribal people to modern urban communities. Medical and cultural geographers also focus on political economy among rural and non-western field settings. 
Historians too do research at the interface of environment and health in industrial societies. Likewise the medical and ecological anthropologists are focused on interrelationships between ecology and health in their studies.

In anthropology, environmental issues are being seen as "cultural in character" (Milton 1996). There are two ways by which the interaction between human beings and environment takes place:

- Culture is essential to their survival because without it, they would not be able to retain from their environment whatever they need to sustain their physical and social well-being (Milton 1996). Such a view is not universally accepted.

- Culture is the medium through which people adapt to, rather than merely interact with the environment (Milton 1996).

The concept of Nature-Man-Spirit complex given by Vidyarthi (1963) explores the interaction between man and its ecological setting. It also deals with the religious beliefs, concept of spirit and supernatural world. The three components, nature, man and spirit are interdependent and mutually complimentary such that the existence of one simple can not be thought in absence of other. The Nature-Man-Spirit complex also focuses on the fact that the equilibrium between nature, man and supernatural forces is very important.

\section{Ecological approaches in medical anthropology}

Since the World War II, anthropologists, both socio-cultural and biological, have turned in increasing numbers to the cross-cultural study of medical systems and to the bio-ecological and socio-cultural factors that influence the incidence of health and disease. In part their interests are theoretical, sparked by the desire to understand human being's behaviour in its widest manifestations; and in part their interests have been applied, motivated by the belief that anthropological research techniques, theories, and data can and should be used in programs designed to improve health care in both developed and developing nations.

An important theoretical analysis of the links between the social environment and illness etiology was provided by Cassel (1974) in the field of public health. This work signals the shift from 'germ theory' towards a more ecologically oriented contextual perspective of effect of one's environment on disease etiology. One of the most early works in the field of ecology and health includes the work by Alland (1970) which describes health conditions of the human population - specifically its disease and fertility rates as a good measure of its environmental adaptation. According to him, a good adapted society would mix some of biological and sociocultural means to achieve low rates of disease and high rates of fertility. The concept of adaptation is used by Alland (1970) in three senses: genetic, physiological and cultural. Applying the concept of ecology to medical anthropology offers an advantage of quantifying how successful or unsuccessful a social system is in meeting the goals of survival and reproduction. This concept has been elaborated by Mc Elroy and Townsend (1996) who adopted the term 'medical ecology' in which the concept of adaptation is used similarly as was used by Alland in 1970 (Joralemon 2010).

Ecological approaches in medical anthropology or simply medical ecology view health and disease as reflections of relationships within a population between neighbouring populations and among the life forms and physical components of a habitat. It considers health to be a measure of how well a group of people has adapted to the environment. Its focus is on the study of survival strategies of small, isolated populations but it is also productive for understanding the health problems of more complex societies. 
Medical ecology studies the dynamic concept of ecosystems that helps in understanding of environmental changes and fluctuations that affect the rates and patterns of disease. It emphasizes the health implications of interactions between human groups and their physical and biological environments. The dynamic concept of ecosystems helps in understanding how environmental changes and fluctuations affect rates and patterns of disease. The comparative perspective of medical anthropology combined with the inter-disciplinary teamwork of medical ecology allows us to consider wide range of human solutions to environmental problems and the health repercussions of those solutions.

Further, a series of development of outside of the discipline of anthropology during 1990s energized a new wave of environmental interest among medical anthropologists at the beginning of $21^{\text {st }}$ century. The first development was the emergence of the term 'biodiversity' (Wilson 1988) and this new term helped to focus concern about the accelerating loss of species due to human-initiated changes in their habitats. The United Nations Conference on Environment and Development held at Brazil in 1992 became the occasion for intense media coverage of threats to biodiversity. The second development was the introduction of 'emerging infectious diseases' (Lederberg et al. 1992). It was highlighted in a 1989 conference on emerging viruses, then in edited scientific volumes such as The Coming Plague (Garrett 1994) and The Hot Zone (Preston 1994). The third development was the increasing recognition of the seriousness of global climate change, crystallized around the Kyoto Protocol in 1997. All these of three lines of development suggest that anthropogenic change in the global environment was far more extensive than formerly thought. This led to the renaissance of interest in ecological approaches in medical anthropology.
The ecological approach in medical anthropology asserts that human societies constantly change and recreate the physical and biological environment to which they must then adapt through the processes of co-evolution of human biology and culture (Townsend 2011). These approaches evaluate the human health and wellness in regard of their total environment including their social environment.

\section{Ecology and epidemiology}

According to May (1958), 'disease is that alteration of living tissues that jeopardizes their survival in their environment'. Epidemiology deals with the distribution in space and the prevalence or incidence of diseases as influenced by natural and man-made environments and by human behaviour (Foster and Anderson 1978). A large number of studies have been conducted on ecology in relation to epidemiology. Livingstone (1958), a physical anthropologist, produced a classic anthropological research on disease ecology in the 1950s in his study of malaria and sickle cell disease in West Africa. Prior to this time, there has been a little discussion on interrelationship between ecology and health. May (1960) observed that some of the people in a Chinese village were seriously affected by a heavy infestation of hookworm, while others were not. An investigation showed that almost all the hookworm patients were rice growers. As the rice growers worked with mud mixed with night soil led them to the hookworm infestation while the other villagers were engaged in silkworm faming, and spent their working days on ladder tending mulberry leaves. Here the disease boundaries and cultural distinctions virtually coincided. In this case, the hookworm infestation involved the complex ecosystem involving the relationships between human and non-human organisms and their environments (cf. Lieban 1973).

Kuru disease is an acute, progressive and degenerative disease of central nervous system 
found among the Fore of the New Guinea highlands. The prevalence of the disease was found to be quite high in the community and it accounted for almost half of the deaths that occurred in the Fore. The Kuru disease was explained as a geographical isolate and found only among the Fore. The disease causation was attributed to ecological conditions, social structure of the community (as the disease was more in women and children, and less in men due to marked physical and social separation), nutrition and toxicity. Parker (1962) attempted to relate the child rearing practices among the Eskimo to the appearance of convulsive hysterical attacks in adult life. The study found roots of adult hysteria in three social situations: (a) a child rearing process that does not prepare the children for crisis situation, (b) institutionalized religious practices which provide socially sanctioned outlets for hostility and role models for hysteria-like behaviour, and (c) social dependency (Fisher and Fisher 1961). The ethnographic fieldwork in 1961 to 1963 by anthropologists Robert Glasse and Shirley Lindenbaum helped to reveal that the Kuru disease emerged in 1920 and might have been transmitted by ritual consumption of infected portions of the brain of the deceased relative. After the abandonment of cannibalism in 1957, the incidence of Kuru began to decline because this disease had a long period of incubation, new cases continued to appear for many years, the researchers who tested the Kuru survivours suggest that Kuru imposed strong balancing selection, and this might have happened more than once in human history (cf. Mead et al. 2009).

Scotch (1963) studied the distribution of hypertension in two Zulu communities, noting the strikingly higher prevalence of this disease in urban as against rural Zulu communities due to greater social stress in the urban setting. Similar example has been provided by Tyroler and Cassel (1964) in western North Carolina in which urbanization led to the increased risk of cardiovascular diseases.

Whiting (1964) analyzed the postpartum sexual taboos and late weaning in protecting the infants against kwashiorkor. He explained that kwashiorkor is largely confined to areas of high temperature and humidity, conditions conducive to the growing of root and fruit crops low in protein. In societies, dependent on such foods, he observed, a lactating mother may help prevent the reduction of already low protein values of her milk - a reduction that could lead to serious illness for her nursing child - so long as she avoids another pregnancy. He also points out the prevention of pregnancy in such societies, without alternative means of contraception, generally is accomplished by abstinence from sexual intercourse. Here the postpartum taboos are socio-cultural practices which reduce the effect of kwashiorkor both by prolonging the nursing period and ensuring that the protein content in lactating mother is not lowered below the danger point (cf. Lieban 1973).

\section{Ecology and infectious diseases}

An important principle of medical ecology is that population, society and both the physical and biological environments are in dynamic equilibrium. The stress on this equilibrium can produce cascading effects on any of the aforementioned components. The humanenvironment relationship, if disturbed enough by major changes in land use, migration, population pressure, or other stressors can show significant maladaptation, as manifested by the appearance or diffusion of new diseases (Mayer 2000). The construction of new irrigation systems in arid areas such as Egypt has augmented the food production but has also lead to various diseases.

The low dam at Aswan was constructed in the 1930 s to allow perennial irrigation of the Nile Valley. Within 20 years, the local prevalence of schistosomiasis rose from about 10 percent to 75 percent. In 1942-43, a malaria epidemic in the 
region followed an invasion by Anopheles gambiae from Sudan, and caused 130,000 deaths (Farid 1977). Further, increase in schistosomiasis and bilharziasis prevalence was reported after the creation of the Aswan high dam at the lake Nasser in the 1960s. Miller (1973) reported that within three years of the construction of the dam, the infection rate among the children aged two to six years rose from 5-25 percent to 55-75 percent. Strickland (1982) argued that throughout 1970s and part of $1980 \mathrm{~s}$, local inhabitants continued to show high prevalence of schistosomiasis. Kloos and Lemma (1977) found the prevalence of schistosomiasis following the irrigation schemes in Awash Valley in Ethiopia.

Lymphatic filariasis had increased 20 fold in the southern Nile Delta since 1960s. It is argued by Harb et al. (1993) that this has been primarily due to an increase in breeding sites for Aedes mosquitoes, which followed a rise in the water table as a result of extension of irrigation. The spread of Rift Valley Fever has been associated with dams and irrigation systems in Egypt and Sudan. The increase in schistosomiasis, malaria and other infectious diseases was also found following the Volta River project in Africa (Stoltman et al. 2004).

In Afganistan, incidence of vivax malaria increased from 5 percent to 20 percent after the Kunduz valley was developed for cultivation of rice, cotton and vegetables (DukhaNina et al. 1975). Similar projects in Kenya, Burundi and Mali were found to be associated with escalating rates of malaria and schistosomiasis (Hunter et al. 1993). Rice cultivation has also been linked to the increased risk of Japanese B Encephalitis in Sri Lanka (Birley 1995). In Burkino Faso, increased prevalence of filariasis and onchocerciasis (river blindness) was noted soon after the creation of the rice irrigation schemes is various parts of the country (Hunter et al. 1993).
The other examples include increase in malaria following land clearance for rubber plantations in Malaysia (Mayer 2000). In Malaysia, the rubber plantations were established in malaria-free areas but after clearance of the native forests, ideal conditions were established for the breeding of Anopheles maculates, with a consequent introduction of malaria. Similarly, the Chagas disease in South America, onchocerciasis in East Africa and Simulium sirbanum and Simulium damnosum vectors in West Africa appeared after the land clearance (Saker et al. 2004). The same thing occurred in south India, where the clearance of native cover in uninhabited hills encouraged the breeding of Anopheles fluviatilis, followed by introduction of malaria. The prevalence of malaria in Brazil increased dramatically as a consequence of colonization and deforestation, particularly in gold mining areas and that there is a high frequency of malaria transmission among gold miners.

Some diseases which were localized or spread slowly in an earlier time are propagated to previously free areas as a result of rapid mass communication made possible by roads, railroads, and air travel. Trypanosomiasis, a tsetse fly vectored protozoal disease, was spread in large parts of Africa due to migration of labour made possible by the development of roadways. In Ghana, migrant labourers from north of the country passing through tsetse fly belt on their way to work in the Ashanti area spread the disease so thoroughly that Ashanti came to have higher rates of infection than the north, where the disease was endemic (Hughes and Hunter 1970). There was an increase in vectored diseases with the construction of transportation routes in Brazil, and the appearance of Lyme disease in the United States following the reforestation of peri-urban areas in the northeast. The reforestation occurred as previously agricultural areas were brought into residential and even commercial usage, thus, 
increasing the proximity of humans and deer which are important in the transmission of Lyme disease (Mayer 2000).

\section{Nutrition and ecology}

The ecological anthropologists based on their ethnographic approach attempted to study health and nutrition among the hunting, gathering and farming communities among in their ecological conditions (Townsend 2011). Thus, they produced a rich body of data concerning subsistence systems, but the attempt to understand any of these populations as an isolated adaptive system in equilibrium with its environment quickly proved inappropriate. Even the seemingly most isolated of these communities were integrated into regional systems of trade. Colonial and neo-colonial conquest had introduced diseases, decimated populations, and radically changed settlement patterns in what superficially appeared to be isolated, traditional societies (Townsend 2011). Bhasin (2004) argued that ecological constraints are high in Ladakh which affects the health status of the people. The accessibility and availability of biomedicine is very less. Thus, Ladakhis depend on their traditional folk medicine (Amchi) and chose biomedicine as their last resort only in cases of terminal illness.

\section{Environment pollution and health}

Some of the cases, particularly the use of pesticides and fertilisers from Punjab are interesting to note. Singh (2008) conducted a study to analyse the soil and water samples from 30 districts of Punjab and found the direct correlation between pesticide use and cancer. Kaur et al. (2011) conducted a study to assess the genetic damage in workers occupationally exposed to pesticides in various districts of Punjab. The study was conducted between 2003 and 2006; blood samples of farmers were collected and tested twice a year. The first 210 samples were collected soon after a day of intensive spraying. The second tests were conducted on 60 farmers from the first group after six months to determine the frequency of DNA repair. She observed that 36 percent of the farmers' blood samples showed significant DNA damage and the worst affected were the cotton, paddy and wheat growers. Smoking, drinking and age were not found to be co-related to the extent of DNA damage.

Thakur et al. (2008) found pesticides such as chloropyrifos and ethion levels above permissible limits in vegetable and fruit samples from Talwandi Sabo of District Bathinda. They also found heptachlor, aldrin and endosulfan from blood samples of cancer patients. The study established a link between pesticide use and cancer.

Tirado (2009) conducted a study in three districts, namely, Bathinda, Muktsar and Ludhiana of Punjab to assess the effects of nitrogenous fertilizers on groundwater and health. A total of 50 samples were collected (18 each from Ludhiana and Muktsar and 14 from Bathinda). The study found that the average application rate is $322 \mathrm{~kg} \mathrm{~N}$ per hectare in 2008-2009 in these three districts is higher than the national average reported by the Fertilizers Association of India for Punjab (i.e., $210 \mathrm{~kg} \mathrm{~N}$ per hectare for 2006-2007). It also related the fertilizer use to cancer and blue baby syndrome. Blaurock-Busch et al. (2010) conducted the hair mineral test on 114 children aged 12 and younger mentally challenged children from Faridkot, Punjab. The test results indicated past and chronic metal exposure for each one of the children and 88 percent of the samples exceeded the uranium reference range for hair.

\section{CONCLUSION}

The ecological approaches in medical anthropology asserts that human societies constantly change and recreate the physical and biological environment to which they must then 
adapt through the processes of co-evolution of human biology and culture (Townsend 2011). These ecological approaches view health not only as a biological issue but a socio-cultural issue as well. Human health and disease derive from the interaction of human's biological potential with numerous environments through socially, culturally and individually mediated experiences that have affect on biological processes (Winkelman 2009). Thus, during recent years more and more anthropologists have become interested in biosocial-environmental health problems that are best studied from what Bates (1953) has described as "ecological point of view". It is not surprising that the ecological point of view has proved congenial to anthropologists since, in reality it is a mere extension of fundamental approach of anthropology i.e., study of systems. In anthropology, the 'integral whole' is a sociocultural system while in ecology, the 'integral whole' is ecosystem.

The present paper is an attempt to interrelate ecology and health by highlighting the bio social concerns relating to these two. Through the mention of specific cases of diseases in Punjab and elsewhere, an attempt has been made to emphasise the role of various biological and socio-cultural determinants affecting the health of an individual in an ecological setting.

\section{REFERENCES}

Alland, A. 1970. Adaptation in Cultural Evolution: An Approach to Medical Anthropology. Columbia University Press, New York.

Bates, M. 1953. Human ecology. In: Anthropology Today. (ed.) Kroeber, A.L. University of Chicago, Chicago.

Bhasin, V. 2004. Sexual illnesses and underutilization of biomedicine among tribal women of Rajasthan. Anthropologist 6(1):112.
Birley, M.H. 1995. The Health Impact Assessment of Development Projects. HMSO, London.

Blaurock-Busch, E., A. Friedle, M. Godfrey and C.E.E. Schulte-Uebbing. 2010. Metal exposure in the physically and mentally challenged children in Punjab, India. Maedica 5(2):102110.

Cassel, J. 1974. An epidemiological perspective of psychosocial factors in disease etiology. American Journal of Public Health 4(11):1040-1043.

DukhaNina, N.N., M.K. Nushin, N.I. Polevoi, G.K. Lakubi and M.M. Artemev. 1975. The malaria problem and malaria control measures in northern Afganistan. Meditsinskaia Parazitologiia I Parazitamye Bolenzi 44:338344.

Farid, M.A. 1977. Irrigation and malaria in arid lands. In: Arid Land Irrigation in Developing Countries. E.B. Oxford, Pergamon, Worthington, pp. 413-429.

Fisher, A. and J.L. Fisher. 1961. Culture and epidemiology: A theoretical investigation of Kuru. Journal of Health and Human Behaviour 2:16-25.

Forde, D. 1934. Habitat, Economy and Society. Menthuen, London.

Foster, G.M. and B.G. Anderson. 1978. Medical Anthropology. John Wiley and Sons, USA.

Garrett, L. 1994. The Coming Plague: Newly Emerging Diseases in a World Out of Balance. Farrar, Straus and Giroux, New York.

Harb, M., R. Faris, A.M. Gad, O.N. Hafez, R. Ramzy and A.A. Buck. 1993. The resurgence of lymphatic filariasis in the Nile delta. Bulletin of the World Health Organization 71:49-54.

Hawley, A.H. 1950. Human Ecology: A Theory of Community Structure. Ronald Press Co., New York. 
Hughes, C.C. and J.M. Hunter. 1970. Disease and development in Africa. Social Science and Medicine 3:443-493.

Hunter, J.M., L. Rey, K.Y. Chu and E.O. AdekoluJohn. 1993. Parasitic Diseases in Water Resources Development. WHO, Geneva.

Joralemon, D. 2010. Exploring Medical Anthropology ( $3^{\text {rd }}$ edition). Prentice Hall, New Jersey, USA.

Kaur, R., S. Kaur and M. Lata. 2011. Evaluation of DNA damage in agricultural workers exposed to pesticides using single cell gel electrophoresis (comet) assay. Indian Journal of Human Genetics 17(3):179-187.

Khalil Bey, M. 1949. The national compaign for the treatment and control of bilharziasis from the scientific and economic aspects. Journal of Royal Egyptian Medical Association 32:820.

Kloos, H. and A. Lemma. 1977. Schistosomiasis in irrigation schemes in the Awash valley, Ethiopia. American Journal of Tropical Medicine and Hygeine 26:899-908.

Kroeber, A.L. 1939. Cultural and Natural Areas of Native North America. University of California Press, Berkeley, USA.

Lederberg, J., R.E. Shope and S.C. Oaks. 1992. Emerging Infections Microbial Threats to Health in the United States. National Academy of Sciences, Washington DC, USA.

Lieban, R.W. 1973. Medical anthropology. In: Handbook of Social and Cultural Anthropology. (ed.) J.J. Honigmann. Rand McNally, Chicago, pp. 1031-1072.

Livingstone, F.B. 1958. Anthropological implications of sickle-cell genes distribution in West Africa. American Anthropologist 60:533-562.

May, J.M. 1958. The Ecology of Human Disease. MD Publications, New York, USA.
May, J.M. 1960. The ecology of human disease. Annual New York Academy of Sciences 84:789-794.

Mayer, J. 2000. Geography, ecology and emerging infectious diseases. Social Science and Medicine 50:937-952.

McElroy, A. and P.K. Townsend. 1996. Medical Anthropology in Ecological Perspective. Westview Press, Boulder, CO, USA.

Mead, S., J. Whitefield, M. Poulter, P. Shah, J. Uphill, T. Campbell, H. Al-Dujally, H. Hummerich, J. Beck, C.A. Mein, C. Verzilli, J. Whittaler, M.P. Alpers and J. Collinge. 2009. A novel protection prion variant that colocalizes with Kuru exposure. New England Journal of Medicine 361:2056-2065.

Miller, M.J. 1973. Industrilization ecology and health in the tropics. Canadian Journal of Public Health 64:11-16.

Milton, K. 1996. Environmentalism and Cultural Theory: Exploring the Role of Anthropology in Environmental Discourse. Routledge, London.

Milton, K. 1997. Ecologies: Anthropology, culture and the Environment. ISSJ 154:477-495.

Parker, S. 1962. Eskimo psychopathology in the context of Eskimo personality and culture. American Anthropologist 64:79-96.

Preston, R. 1994. The Hot Zone. Random House, New York, USA.

Rappaport, R. 1971. Nature, culture and ecological anthropology. In: Man, Culture and Society. (ed.) Shapiro, H.L. Oxford University Press, Oxford, UK.

Saker, L., K. Lee, B. Cannito, A. Gilmore and D. Campbell-Lendrum. 2004. Globalization and Infectious Diseases: A Review of Linkages. Centre on Global Change and Health, UK.

Salzman, P.C. and D.W. Attwood. 2002. Ecological anthropology. In: Encyclopedia of 
Social and Cultural Anthropology. (eds.) Barnard, A. and J. Spencer. Routledge, New York, pp. 169-172.

Scotch, N. 1963. Sociocultural factors in the epidemiology of Zulu Hypertension. American Journal of Public Health 53(8):1205-1213.

Singh, B. 2008. Cancer Deaths in Agricultural Heartland: A Study in Malwa Region of Punjab. available on www.itc/library/papers_2008/msc/gem/bajinde rpdf.pdf.

Steward, J. 1968. Cultural ecology. In: International Encyclopedia of Social Sciences. (ed.) Sills, D. Macmillan Company, New York, 4:337-344.

Steward, J. 1973. Theory of Culture Change: The Methodology of Multilinear Evolution. University of Illinois Press, Urbana.

Stoltman, J.P., J. Lidstone and L.M. DeChano. 2004. International Perspectives on Natural Disaster: Occurrence, Mitigation and Consequences. Kluwer Academic Publishers, Neatherlands.

Strickland, G.T. 1982. Providing health services on the Aswan high dam. World Health Forum 3:297-300.

Thakur, J.S., B.T. Rao, A. Rajwanshi, H.K. Parwana and R. Kumar. 2008. Epidemiological study of high cancer among rural agricultural community of Punjab in
Northern India. International Journal of Environmental Research and Public Health 5:399-407.

Tirado, R. 2009. Chemical Fertilisers in Our Water. Greenpeace Society, India.

Townsend, P.K. 2011. The ecology of disease and health. In: A Companion to Medical Anthropology. (eds.) Singer, M. and P.I. Erickson. Wiley-Blackwell, UK, pp. 181-195.

Tyroler, H.A. and J. Cassel. 1964. Health consequences of culture change: The effects of urbanization on coronary heart mortality in rural residents. Journal of Chronic Diseases 17:167-177.

Vidyarthi, L.P. 1963. The Maler: Nature-manspirit Complex in a Hill Tribe of Bihar. Bookland Private Limited, Calcutta.

White, L. 1959. The Science of Culture: A Study of Man and Civilization. Farrar Strauss, New York.

Whiting, J.W.M. 1964. Effects of climate on certain cultural practices. In: Explorations in Cultural Anthropology. (ed.) Goodenough, W.H. McGraw-Hill, New York pp. 511-544.

Wilson, E,O, 1988. Biodiversity. National Academy Press, Washington.

Winkelman, M. 2009. Culture and Health: Applying Medical Anthropology. Jossey-Bass, San Francisco, USA. 